\title{
Microcomputers in antenatal care: a feasibility study on the booking interview
}

\author{
R J LILFORD, T CHARD
}

The potential application of computers for recording and analysing patient data has been recognised for many years, ${ }^{1-11}$ though widespread use has been hampered by practical factorsin particular, cost and dependence on monolithic centralised systems. Nevertheless, the considerably reduced price, compact size, and simplified handling of the newer "micro" computers based on the microprocessor promise to revolutionise medical care. $^{12}$ We describe an interactive system for acquiring a full patient history at the time of the first antenatal visit (booking visit).

\section{Equipment}

The three items of "hardware" required are detailed in the table and illustrated in figure 1 .

\section{Hardware requirements}

\begin{tabular}{|c|c|c|c|}
\hline Item & Manufacturer & Memory & $\operatorname{Price}(\mathscr{f})$ \\
\hline Computer & Commodore PET ( 40 column & 30 Kilo bytes* & 695 \\
\hline $\begin{array}{l}\text { Memory } \\
\text { Printer }\end{array}$ & $\begin{array}{l}\text { Computhink Dual Disk Drive } \\
3022 \text { Commodore } 80 \text { column } \\
\text { matrix printer (with } \\
\text { programmable line feed and } \\
\text { tractor drive) }\end{array}$ & 800 Kilo bytes* & $\begin{array}{r}1145 \\
425\end{array}$ \\
\hline
\end{tabular}

*One "byte" represents a single character-for instance, letter or number-and is itself made up of eight units of binary code.

Note that there are several alternative systems from different manufacturers, all very similar in price or specification.

Departments of Obstetrics and Gynaecology, and Reproductive Physiology, St Bartholomew's Hospital Medical College and the London Hospital Medical College, London EC1

R J LILFORD, MRCP, MRCOG, lecturer

T CHARD, MD, FRCOG, professor

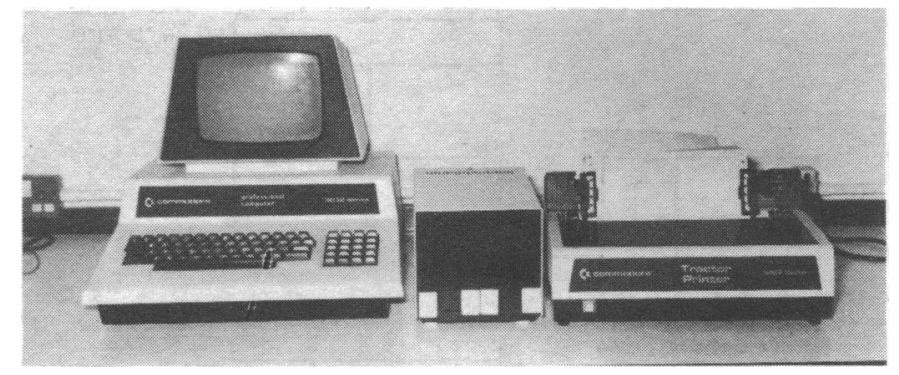

FIG 1-Computer is linked to "floppy" disc unit, which stores programs and case histories. Optionally, the material may be printed out through the interfaced printer.

\section{General structure of the system}

The programs (software) are designed to take the history by displaying a series of questions on the visual display unit (VDU). The answers are entered on the keyboard by a member of the medical staff (fig 2). We have aimed at including every possible aspect of an ideal history without any need for entry of unstructured discursive information.

Figure 3 shows the general structure of the system. Because of constraints on the memory capacity of the microcomputer itself, four separate programs are required. These are stored on one disc and are loaded on to the computer in a logical sequence after a single instruction from the keyboard. The data obtained from the patient are recorded on a second disc, from which they can be retrieved and displayed on the VDU. They are also typed out by the printer to provide a "hard copy" of the patient's history. This is then attached to the first page of the obstetric folder.

\section{Detailed program structure}

Each program is divided into several sections. A series of questions relevant to the section is displayed on the screen and the answer is 
typed in through the keyboard: the answer may take the form of a word-for example, a patient's name (fig 4)-a Yes/No (fig 5), or a number selected from a list on the screen (fig 6). The conventional history is simulated in that subsequent questions are selected on the basis of the previous answer. For example, if the question "Has the patient used contraception?" is answered "yes" then the program automatically branches to a series of questions about contraception. Figure 7 shows an example of this type of selective branching.

The program includes explanatory notes, error traps, and reminders. Explanatory notes are displayed on demand and include items such as a list of possible contraceptive agents and definitions of

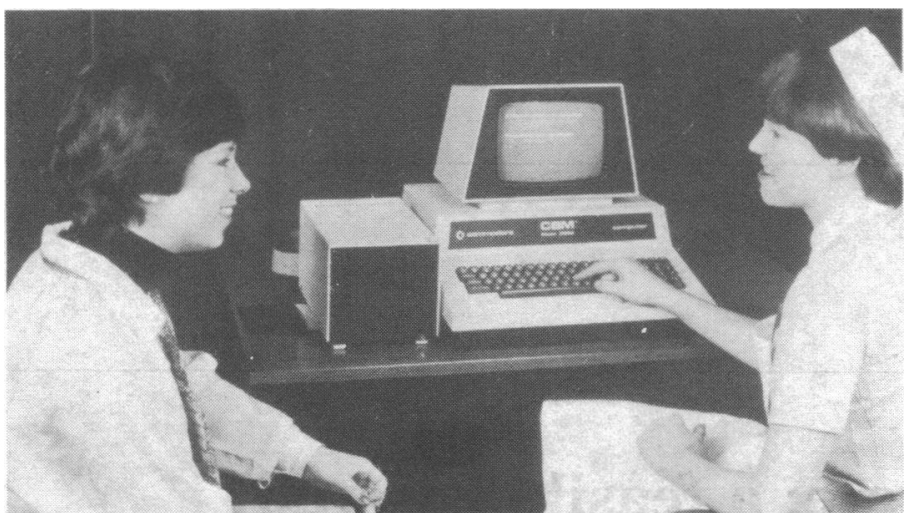

FIG 2-The nurse, seated beside the patient, answers questions which appear on screen.

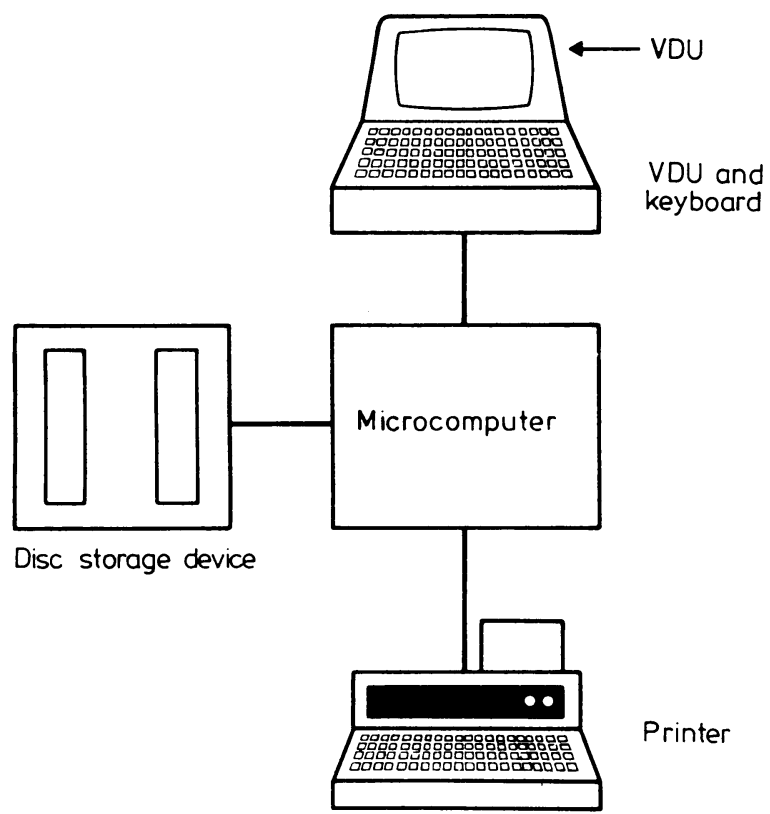

FIG 3-Schematic diagram showing linkage of central processing unit (microcomputer) with computer terminal, screen, memory device, and printer. (In reality the microcomputer is housed within same terminal as keyboard and visual display unit (VDU).

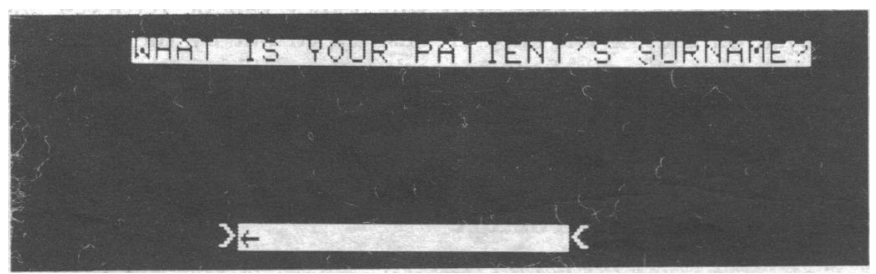

FIG 4-Certain questions can be answered only by a proper noun. The word appears in the striped field as it is typed and any errors can be corrected.

\section{IS THE PATIENT MARRRIED IA LAID?} AINSWER Y OR N

FIG 5-A simple " $\mathrm{Y}$ " or " $\mathrm{N}$ " answer is required to most questions.

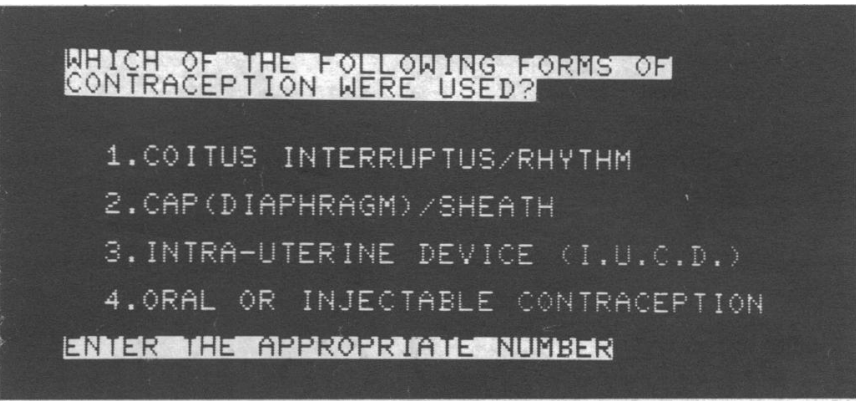

FIG 6-A number is selected in order to answer certain questions.

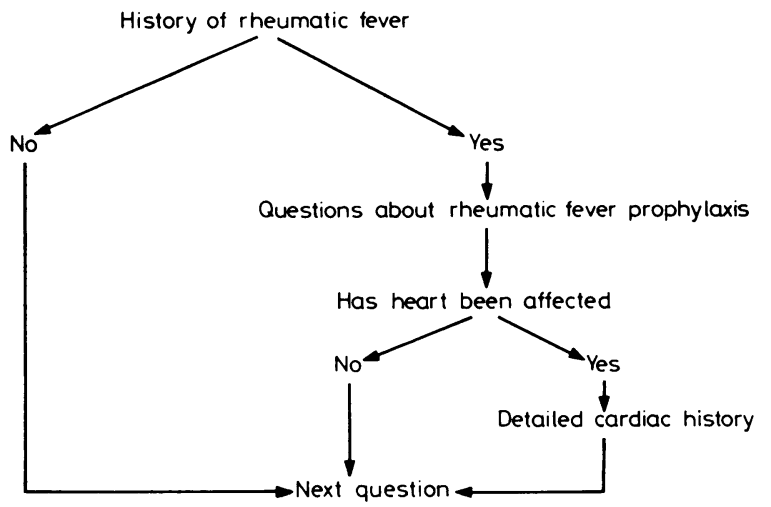

FIG 7-An example of a selective branching pattern in the history.

commonly used obstetric terms. An example of an error trap is a subroutine that examines all data to determine whether they have been properly "inputted" and, if so, whether they are feasible. Reminders highlight important clinical features and may be associated with specific advice-for example, if a women is 37 or older the clinician is reminded that amniocentesis should be considered.

The programs were written in BASIC. This "language" is relatively easy to use, no knowledge of programming is required of the users themselves, and running the program from prerecorded discs is no more demanding than using a typewriter and a record player.

\section{Date storage and retrieval}

The answers to all questions are coded by the computer and recorded automatically on a disc. Each answer is stored as a variable character or string of characters. These are assembled into a series of records that constitute the history of an individual patient. A single disc of the type used in this study can accommodate 400 histories.

Data is retrieved from the disc by inputting the patient's hospital number. The disc is searched automatically for the first record of this patient (about 10 seconds), and the user then selects the required aspect of the history. Alternatively, the records may be reviewed in sequence, rather like turning the pages of a book. Figure 8 shows one such "page" of a patient's history.

\section{Clinical experience with the computerised booking system}

Fifty patients gave informed consent to have their history taken on the computer. The first 20 histories were taken by one of us (RL) and 


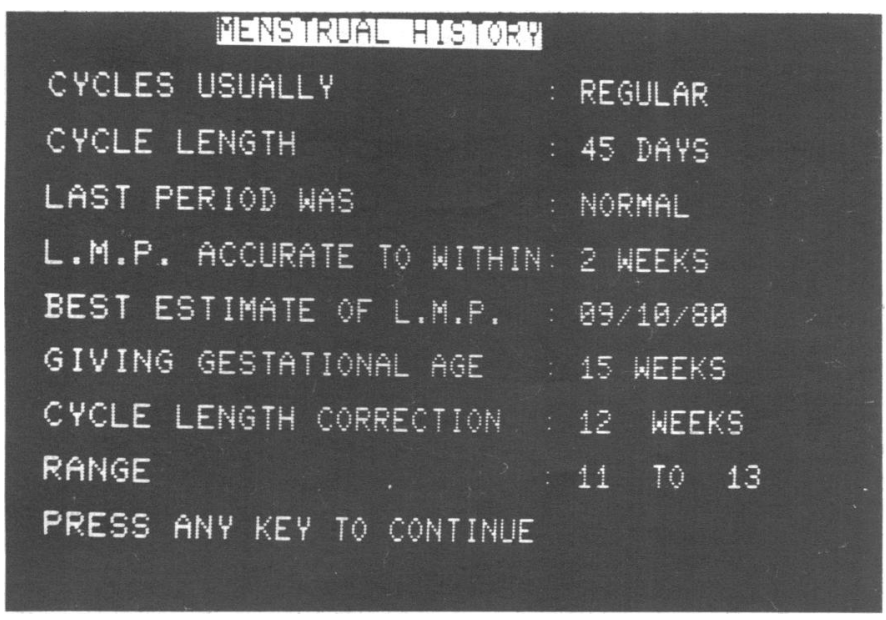

FIG 8-History is retrieved as formatted pages with protected "template" on left. Data are displayed in unprotected field on right.

subsequently by members of the nursing staff with no prior computing experience.

Though a formal study of consumer attitudes was not attempted, there were no serious objections from either patients or staff; indeed, the contrary was often the case, though this can be partly ascribed to the novelty of the procedure.

The interview took somewhat longer than usual: firstly, because the history is rather more detailed than is the normal practice; secondly, staff were unfamiliar with the system, especially keyboard entry. A comparison of computer versus manual history taking was made in 10 cases. For the non-obstetric history the median time was 13 minutes (computer) as against 11 minutes (normal); for each previous pregnancy the figures were seven minutes and four minutes respectively.

The computerised history was found to have several advantages over conventional methods:

(1) All users were agreed that the structure of the history and the amount of clearly defined information available for subsequent recall is much superior to that of the usual record. A notable example is the menstrual history. In a normal system ambiguous information is often recorded as "?LMP" (last menstrual period) without specifying the nature of the "?." Further inquiry at a later stage, perhaps when considering induction of labour, must inevitably be less efficient. By contrast, the computerised system defines and records the definition of the "?"-does it mean totally unknown, or known to within plus or minus two weeks, or doubtful because of an ambiguity in the bleeding pattern?

(2) Convenience factors, such as automatic calculation of gestational age, expected date of delivery, and conversion of weights to metric units were well appreciated.

(3) Presentation of retrieved information as a neatly typed page of well-formatted text on the screen was highly commended-a major advantage over the variable quality of traditional manuscript.

(4) Memory aids (fig 9) are a valuable feature since the routine checks that form a large part of obstetric practice are more reliably carried out by mechanical means. The introduction of more tests in

FHATLT THABE

FIRST NAME

AGE

COUNTRY OF ORIGIN

OCCUPATION

H'BAND'S OCCUPATION : POLITICIAN

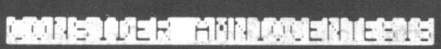

\section{PRESS ANY KEY TO CONTINUE}

the future will increase the scope for errors of omission and enhance the value of computer-aided memory.

A general complaint from non-committed users was the inability to record information other than that included on the program. Most complaints were valid and were corrected during the course of the project. Others-such as discursive remarks on the patient's personality-were not easily accommodated. Nevertheless, practical acceptance of systems of this type may demand a facility for unstructured comment and this could be readily included, albeit with some loss of memory space.

\section{Further developments of the system}

The system described here is intended as a feasibility study, and many further developments are intended. Additional software will be designed to update the record, covering all aspects of antenatal care, up to and including delivery and the puerperium, together with the results of laboratory and other investigations. Additional functions will also be developed. Thus the system we have described is largely a passive electronic notebook, albeit with certain important clinical reminders. A more comprehensive program could correlate information as it is entered from different sources. For example, cases in which a raised alpha-fetoprotein may be "missed" because of an overestimation of the gestational age will be recognised automatically as the ultrasound result comes in. Individual risk factors can be combined to generate an overall risk score for use in diagnosis and therapeutic decision making. ${ }^{13-17}$ Computers may also be used as large and frequently updated medical textbooks, an increasing need as medical knowledge expands. Finally, a fully computerised system would greatly facilitate the retrospective analysis of obstetric data from a given unit. This procedure is currently hampered by the often inadequate nature of manual clinical notes and the likelihood of transcription errors. ${ }^{18}$

The development of these programs and their practical use will have important implications in terms of hardware:

(1) To receive and display patient information in all parts of the obstetric unit some 12 microcomputers would be needed.

(2) These terminals will be linked to a central memory device forming a network of microcomputers. The necessary technology has recently been developed in, for example, the Nestar system by Zynar Limited. This will be fundamentally different from existing medical data-handling systems, which depend on passive terminals gaining access to data through a large central processor. The proposed system of "intelligent" terminals offers far greater computing power for lower unit cost, and will allow us to develop gradually to an unspecified final number. Given that the cost of an intelligent microcomputer (c $£ 500-£ 800$ ) is actually less than that of many passive terminals, and that a central hard-disc unit and file-server is much less expensive (c $£ 10000$ ) than a central processor capable of controlling multiple terminals (c $£ 25000$ ), the cost-advantage of the microcomputer system is obvious.

\section{Conclusion}

The system we have described is a prototype for what, by the end of the century, may be regarded as a conventional and uncontroversial part of an antenatal clinic. The advantages offered are considerable, and we believe that the change to computerised recording must occur as certainly as printing replaced the manuscript. Although the concept of electronic note-taking and diagnosis is not new, it has only recently become a practical proposition on a large scale.

The introduction of new technology usually carries some disadvantages, and computerised records have been criticised on several points. It has been claimed, for instance, that computerisation leads to an impersonal service. This would not apply to our system, where the computer merely replaces a pen. We strongly deny that the physical presence of a computer depersonalises the staff-patient relationship, and in our experience a friendly atmosphere was engendered. Even when computerised histories have been obtained directly from the patient without the help of trained staff favourable responses have been reported. ${ }^{19}$

Computerised records have been regarded as a threat to 
medical secrecy. This problem is less applicable to systems such as ours, which are self-contained and not linked to any external data bank. Such systems may actually increase the privacy of patients' records. ${ }^{20}$ Confidentiality can be further protected by demanding entry of specific codes by anyone wishing to retrieve information, ${ }^{21}$ and some current systems-for instance, the Nestar-incorporate this facility in the network file-server software. In this way data files may be made available to authorised personnel only. Similarly names can be excluded from data retrieved for research purposes.

The possibility of technical failure once the fully computerised system is introduced is the most serious concern. For this reason the written record should not be discarded until all the technical problems have been solved. The proposed microcomputer-based network, however, has a considerable advantage as failure of one station leaves all other components unaffected.

We thank the medical and nursing staff in our department for their enthusiastic co-operation.

\section{References}

1 Hofferberth B, Gottschaldt M. The writing of a case history in a neurological department with computer application. Methods of Information 1978;17:162-6.

2 Gabrieli ER. Blueprint of an obstetric information system. Fournal of Computing $1974 ; 3$ :382-406.

${ }^{3}$ Retief AE. Recording of genetic patient data. $S$ Afr Med F 1979;3:1073-6.

4 Gifford S, Maberry D. An integrated system for computerised patient records. Hosp Community Psychiatry 1979;30:532-5.

5 Gabrieli ER. Medical information system, health records and knowledge banks. Med Instrum 1978;12:245-7.
6 McShan D, Haumann D, Glicksman AS. A new interactive computerised data base and retrieval system. Computer Progams in Biomedicine 1979;9: 284-92.

${ }^{7}$ Friedman RB, Korst DR, Schultz JV, Beatty E, Entine S. Experience with the simulated patient-physician encounter. F Med Educ 1978;53: 825-30.

${ }^{8}$ Hensing S. Computers and the health care industry. Dimens Health Serv $1979 ; 56: 22-6$.

9 Barnett GO, Winickoff R, Dorsey JL, Morgan MM, Lurie RS. Quality assurance through automated monitoring and concurrent feedback using a computer-based medical information system. Med Care 1978; $16: 962-70$.

${ }^{10}$ Grossman JH, Barnett GO, McGuire MT, Swedlow DB. Evaluation of computer-acquired patient histories. F $A M A 1971$;215:1286-91.

11 Robinson OW, Walmsley GL, Horrocks JC, et al. Histories obtained by two-stage questionnaire with automated transcript in specialist gynaecological practice $\mathrm{Br}$ Med 7 1975;iv :510-3.

12 Shipton HW. The microprocessor, a new tool for the biosciences. Annual Review of Biophysics and Bioengineering 1979;8:269-86.

13 de Dombal FT, Horrocks JC, Staniland JR, Gill PW. Simulation of clinical diagnosis : a comparative study. $B r$ Med f 1971 ;ii :575-7.

14 Llewelyn DEH. Mathematical analysis of the diagnostic relevance of clinical findings. Clin Sci Mol Med 1979;57:477-9.

15 Card WI, Emerson PA. Test reduction: III-Practical applications. Br Med F $1980 ; 281: 656-8$.

${ }^{16}$ Card WI, Rusinkiewicz M, Phillips CI. Utility estimation of a set of states of health. Methods Inf Med 1977;16:168-75.

17 Teather D. Statistical techniques for diagnosis. Fournal of the Royal Statistical Society $1974 ; 13: 231-44$.

18 Randall CL. The obstetric record. Fournal of Clinical Computing 1974;3: 435-7.

19 Dove AW, Wigg P, Clarke JHC, et al. The therapeutic effect of taking a patient's history by computer. $\mathcal{F} R$ Coll Gen Pract 1977 ;27:477-81

${ }^{20}$ Palmer P, Rees C. Computing in general practice: A report for the General Medical Services Committee of the British Medical Association. London: BMA, 1980:64. (Scicon Report.)

21 Gabrieli ER. Ethical aspects of health records. Fournal of Clinical Computing $1975 ; 4: 283-97$

(Accepted 5 Fune 1981)
If newspaper is used as a constituent in garden compost is there a risk from increased lead ingestion after eating vegetables grown where it is used ?

The use of composted newspaper as fertiliser should not increase the lead contents of food grown in such soils above the natural level. Most plants do not take up appreciable amounts of lead from the soil, although brassicas take up more than most other food crops. The newsprint itself should contain only the amount of lead found in the raw material-namely, wood pulp (range 0.4-2.0 ug/g dry weight). ${ }^{1}$ The ink is composed of oil and carbon black. No appreciable amount of lead should be transferred from the type to the printed page. - Committee on Biological Effects of Atmospheric Pollutants. Lead: airborne lead
in perspective. Washington DC: National Academy of Sciences, 1972. (LC 71-186214.)

In the event of a nuclear explosion how safe would it be to eat animals or plants exposed to radiation?

When considering whether it is safe to eat plants or animals exposed to radiation and fallout from nuclear explosions, it should be clearly understood that it will not be necessary to entertain the possibility of any radioactivity being induced in exposed living material as a result of the radiation dose received. The energy quanta of the radiation produced by any nuclear device, however large, are far below those necessary to induce artificial radioactivity, and the fast neutrons invariably produced are equally unable to induce artificial radioactivity on passage through the animal or plant. The obvious example is the proposed use of the neutron bomb, which exerts its lethal effects purely by radiation effects on living matter but leaves everything else, including the exposed organisms, completely non-radioactive. The main problem relates to the contamination of the outer surface of plants and the skin and interior surfaces of animals by radioactive fallout, the nature of which will depend on the type of the nuclear device exploded. Hence decontamination should be carried out as soon as possible by immediate slaughter of exposed animals and removal of skin, the whole of the lung, respiratory tract, and gut including all internal organs, all blood, and milk. The meat should be preserved at once by deep freezing or other form of preservation. The advice not to slaughter animals until onset of radiation sickness overlooks the fact that animals will continue to be contaminated by fallout ingested during feeding and will produce meat of poor quality as a result of deteriorating health. Since irradiation is used to inhibit germination of plants, the effects of a nuclear explosion are likely to be interference with further growth, but safe consumption would depend on proper decontamination.

In animals exposed to nuclear fallout, whether or not they suffer from radiation sickness, all meat is safe to eat. Only skin, bone, and internal organs or offal, as well as milk, will contain radioactive fallout if animals survive the explosion. Flesh would not be more dangerous to eat if animals are slaughtered in the later stages of radiation sickness, but the flesh would be of poorer quality due to the ill health of the animal. No additional microbiological hazards are expected as a result of irradiation. Plants normally take up minerals from the soil together with certain radioactive isotopes derived from fallout. Exposed crops should therefore be used immediately, if possible, rather than being allowed to accumulate radioactive material from the contaminated environment.

Could staff who give many desensitising injections themselves develop. atopic symptoms, whether from direct skin contact with the injection fluid or by aerosol inhalation when preparing the syringes?

I have never heard or read of this happening, but it is certainly a possibility in an atopic person, particularly if the injection technique is poor. Air in the syringe should always be expelled into the vial. The risk may also be reduced by a scrupulous no-touch technique and, if necessary, by wearing gloves. There may also be a very small risk of contact sensitivity from skin testing solutions because the outside of the bottles may become contaminated, particularly those with push-in stoppers. 